\title{
Thrombus risk versus bleeding risk: a clinical conundrum
}

\author{
Elisabeth $\mathrm{Ng}{ }^{\oplus 1}$ Adel Ekladious, ${ }^{2}$ Luke P Wheeler ${ }^{3}$
}

${ }^{1}$ Alfred Health, Melbourne,

Victoria, Australia

${ }^{2}$ Department of General

Medicine, Goulburn Valley

Health, Shepparton, Victoria, Australia

${ }^{3}$ School of Medicine, University of Notre Dame, Fremantle, Western Australia, Australia

\section{Correspondence to Dr Elisabeth $\mathrm{Ng}$, elisabethhng@gmail.com}

Accepted 25 January 2019

\section{Check for updates}

(C) BMJ Publishing Group Limited 2019. No commercial re-use. See rights and permissions. Published by BMJ.

To cite: $\mathrm{Ng} \mathrm{E}$, Ekladious A, Wheeler LP. BMJ Case

Rep 2019;12:e228344.

doi:10.1136/bcr-2018-

228344

\section{SUMMARY}

A 62-year-old man presented to the Emergency

Department with dyspnoea and central pleuritic chest pain radiating posteriorly to between the scapulae. His medical history included hypertension, osteoporosis and chronic kidney disease secondary to focal segmental glomerulosclerosis with relapsing nephrotic syndrome. Significant examination findings included a loud palpable P2 and a displaced apex beat. An ECG revealed sinus tachycardia with a right-bundle branch block and p-pulmonale. A CT pulmonary angiogram and aortogram demonstrated extensive bilateral pulmonary emboli and a descending thoracic aortic dissection. Subsequent ultrasound of the lower limbs confirmed an extensive, non-occlusive deep vein thrombosis in the right calf. Management of this patient involved therapeutic anticoagulation and tight blood pressure control, with plans for surgical repair delayed due to worsening renal impairment and subsequent supratherapeutic anticoagulation. Co-existence of an aortic dissection and PE has been rarely described and optimal management remains unclear.

\section{BACKGROUND}

Pulmonary embolism (PE) and deep vein thrombosis (DVT) are relatively common presentations, managed in both the inpatient and outpatient settings. Treatment usually involves commencing an anticoagulant medication regime and undertaking clinical review as appropriate. However, a risk versus benefit analysis is critical to minimise the risk of, and ideally avoid, iatrogenic bleeding. With relatively rarer conditions such as aortic dissection, which may require vascular surgical intervention, preventing extension of the dissection is a priority and this may involve cessation of anticoagulation. Therefore, in the rare case of coexistence of these conditions, treatment and management can pose a challenge with few specific guidelines in existence.

\section{CASE PRESENTATION}

A 62-year-old man presented to a rural hospital emergency department after being awakened by sudden onset dyspnoea and central pleuritic chest pain radiating to his scapulae. His medical history included hypertension, osteoporosis and stage III chronic kidney disease (secondary to focal segmental glomerulosclerosis with relapsing nephrotic syndrome). His medications included azathioprine, prednisolone, prazocin, perindopril and alendronate.

The patient was an independent retiree who lived alone at home, with a 40-pack-year history of smoking and moderate alcohol intake. Family history included myocardial infarction at age 60 on the paternal side and no significant medical history on the maternal side.

The patient appeared mildly distressed and initial observations demonstrated tachycardia (100 bpm) and hypertension $(160 / 90 \mathrm{~mm} \mathrm{Hg})$, while afebrile with an oxygen saturation of $99 \%$ on room air. The cardiovascular exam revealed a loud P2, a pansystolic murmur and a palpable second heart sound with a displaced apex beat. The respiratory, neurological and abdominal examinations were unremarkable.

\section{INVESTIGATIONS}

On arrival to the emergency department an ECG was performed which showed sinus tachycardia with a new right-bundle branch block, poor R-wave progression and p-pulmonale when compared with an old ECG. Prompted by high clinical suspicion for a PE, the patient was referred for a computed tomography (CT) pulmonary angiogram and aortogram with contrast, which revealed extensive bilateral pulmonary emboli. Incidentally, the CT image also revealed an aortic dissection of the descending thoracic aorta down to the level of the diaphragm (figures 1 and 2). To investigate the origin of the thrombus, a lower limb ultrasound was requested, and a non-occlusive right calf DVT was visualised.

\section{TREATMENT}

Given the imaging findings, the patient was referred for transfer to a tertiary hospital with an intensive care unit and access to haematology and vascular surgical services. He was stabilised and transferred by the Adult Retrieval Service to the metropolitan site.

On admission to the intensive care unit, blood pressure control was achieved by continuous labetalol infusion, with no other agents required. He was reviewed by the vascular surgery team and deemed to be in need of surgical repair of his aortic dissection. However, management of his high clot burden required further attention before surgery could be safely undertaken.

The haematology department was consulted on the fine balance of anticoagulation and increased 


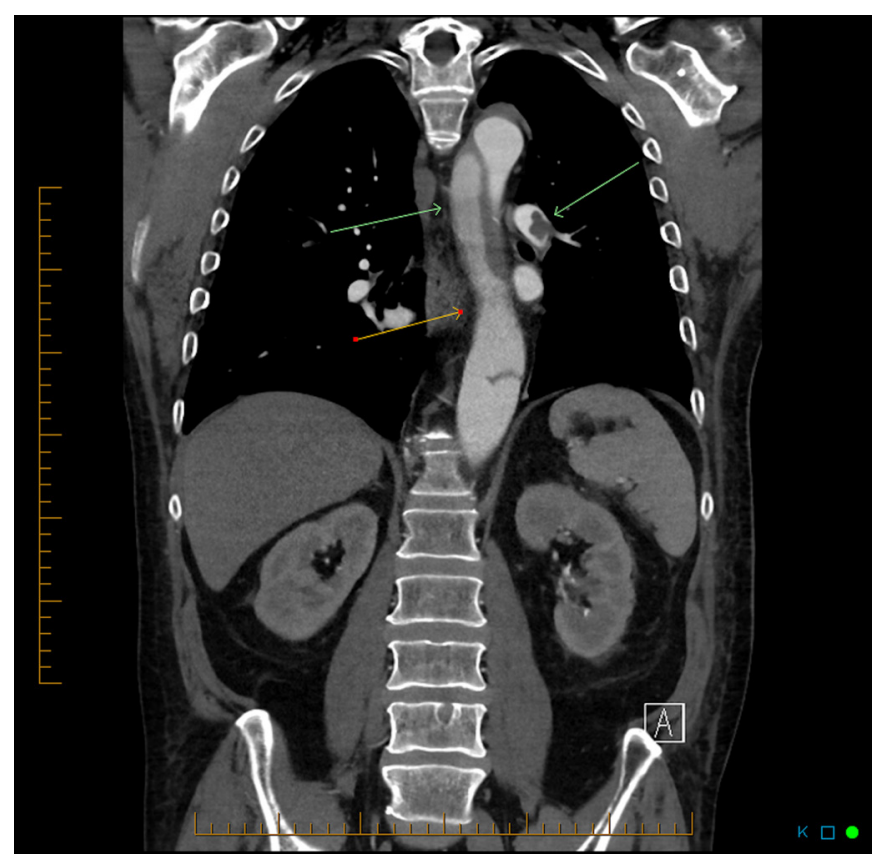

Figure 1 Coronal view CT image demonstrating a type B aortic dissection and large filling defect in the pulmonary trunk (as indicated by the arrows).

bleeding risk. On careful review of his case, it was advised that anticoagulation would be best achieved by a direct Xa inhibitor, insertion of an inferior vena cava (IVC) filter by the interventional radiologist and close monitoring of coagulation profiles.

Unfortunately, his management was complicated by development of acute on chronic renal impairment, and supratherapeutic anti-Xa levels. The acute renal impairment was thought to be iatrogenic, as a result of repeated CT imaging with contrast and the administration of new pharmacological therapeutic agents. Fortunately, haemodialysis was avoided during this admission. Haematology advised cessation

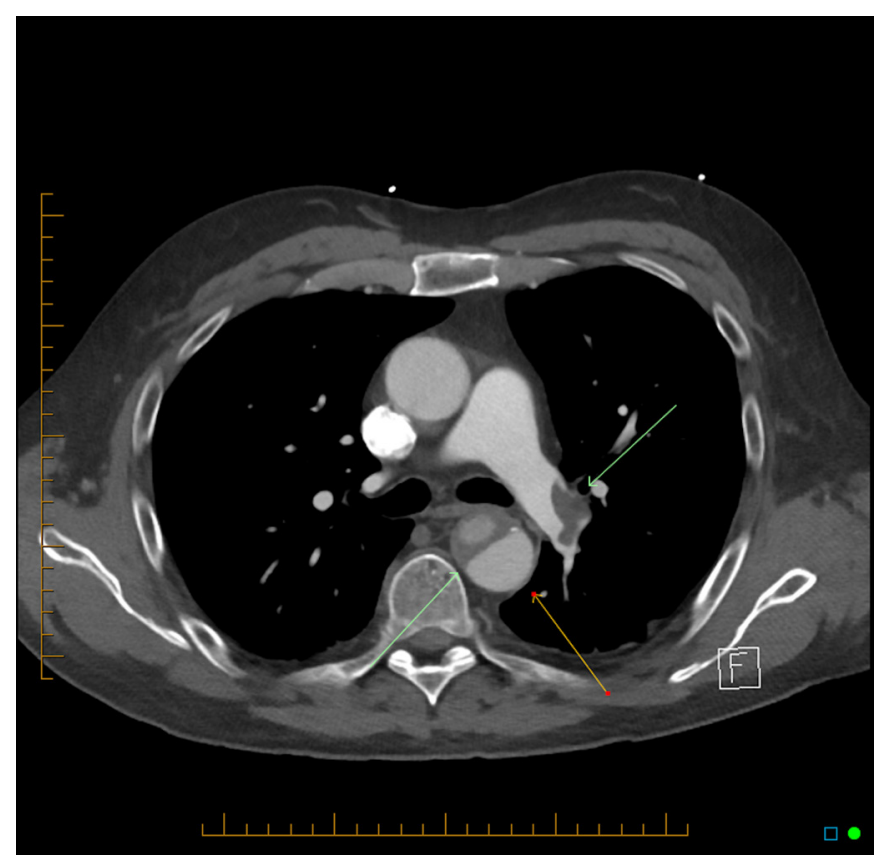

Figure 2 Transverse view CT image demonstrating a type B aortic dissection and large filling defect in the pulmonary trunk. of the direct $\mathrm{Xa}$ inhibitor, to be replaced by enoxaparin, with ongoing close monitoring of his coagulation profile and drug levels. Insertion of the IVC filter was delayed as a result of these complications, thus delaying surgical intervention.

Following case discussion and debate among the surgical and medical teams involved, it was agreed that given the aortic dissection was stable on repeat imaging, the risk of further renal insult (particularly from IVC filter insertion) should surgical management be pursued likely outweighed the benefit. Thus, it was decided that a measured approach would be pursued to allow renal recovery, and plans were made for elective surgery at a later date. After a period of observation and stabilisation, he was transferred back to the rural hospital, with planned follow-up for endovascular repair after recovery of renal function.

\section{OUTCOME AND FOLLOW-UP}

On return to the rural hospital, the patient's renal function was closely monitored and found to improve significantly, approaching baseline function. The patient underwent a V/Q scan (to avoid further renal insult) which was negative for any mismatch defect, consistent with resolution of his pulmonary emboli.

In the following weeks, as planned, the patient was reviewed by the vascular surgical team and underwent endovascular repair of his type B aortic dissection, with no postoperative complications. The multidisciplinary team reviewed the patient's case, and deemed the IVC filter no longer necessary, however agreed that indefinite anticoagulation would be beneficial in this patient given the occurrence of an unprovoked extensive pulmonary emboli. This was achieved by transitioning from enoxaparin to warfarin for ongoing anticoagulation.

\section{DISCUSSION}

Current literature and guidelines suggest that theco-existence of venous thromboembolism, PE and aortic dissection is rare. ${ }^{1-3}$ As such, there is scarcity in the literature of such cases and optimal management. A cohort study by Lee $e t a l^{4}$ found that an aortic aneurysm serves as a risk factor for the development of DVT. ${ }^{4}$ Kuivaniemi et $a l^{5}$ suggested this phenomenon was likely to be due to triggering of an inflammatory reaction following the degeneration of the tunica media within the aorta. ${ }^{5}$ Two other case studies described presentations consistent with a PE, later demonstrated on imaging to be pulmonary artery occlusion as a result of extension of an acute aortic dissection. In these cases, management focused primarily on repair of the aortic dissection, which in-turn improved the pulmonary artery occlusion. ${ }^{67}$

Management of relatively more common presentations such as vertebral artery dissection with embolisation to the posterior cerebral artery has been established by clinical guidelines. ${ }^{8}$ However, there remains a paucity in the literature about the optimal management of aortic dissection with simultaneous or subsequent PE. As such, current practice varies on a case-by-case basis, determined by local expert opinion and careful consideration of patient comorbidities and risk factors.

This case exemplifies some of the challenges encountered when treating a patient with an aortic dissection and PE, given treatment options for one condition may act as a limiting factor to optimal treatment of the other in isolation. ${ }^{9}$ This case highlights the need for consideration of this scenario in relevant clinical guidelines, to aid clinicians who may face a similar management dilemma. 
Learning points

- Consider the possibility of both a pulmonary embolism (PE) and aortic dissection occurring simultaneously when the clinical presentation is suggestive, and pursue adequate diagnostic imaging.

- In difficult and rare clinical scenarios where there are no clear guidelines available, specialty team involvement and multidisciplinary discussion is necessary to guide individual case management.

- There is a need for stronger evidence-based recommendations to guide the diagnosis and management of $\mathrm{PE}$ and aortic dissection when they occur concurrently.

Acknowledgements The authors would like to acknowledge Dr Priyanka Gahlot for her assistance with selecting and labelling the featured images.

Contributors LW provided supervision and contributed to editing of the manuscript. AE identified this as a case with learning points and contributed to conception of the manuscript. EN contributed to the drafting and editing of the manuscript.

Funding The authors have not declared a specific grant for this research from any funding agency in the public, commercial or not-for-profit sectors.
Competing interests None declared.

Patient consent for publication Obtained.

Provenance and peer review Not commissioned; externally peer reviewed.

\section{REFERENCES}

1 Leu HB, Yu WC. Images in cardiology: Massive pulmonary embolism in a patient with type A aortic dissection. Clin Cardiol 2005;28:53.

2 Rau AN, Glass MN, Waller BF, et al. Right pulmonary artery occlusion secondary to a dissecting aortic aneurysm. Clin Cardiol 1995;18:178-80.

3 Chai DZ, Zhang HY, Zhang F. Pulmonary embolism and stanford type B aortic dissection in the same patient. J Vasc Med Surg 2015;3:226.

4 Lee F-Y, Chen W-K, Chiu C-H, et al. Increased risk of deep vein thrombosis and pulmonary thromboembolism in patients with aortic aneurysms: A nationwide cohort study. PLoS One 2017;12:0178587.

5 Kuivaniemi $\mathrm{H}$, Ryer EJ, Elmore JR, et al. Update on abdominal aortic aneurysm research: from clinical to genetic studies. Scientifica 2014;2014:564734-.

6 Higashi S, Mitake H, Eimoto A, et al. [Occlusion of the right pulmonary artery due to acute dissecting aortic aneurysm]. Nihon Kyobu Geka Gakkai Zasshi 1991;39:1217-9.

7 Neri E, Toscano T, Civeli L, et al. Acute dissecting aneurysm of the ascending thoracic aorta causing obstruction and thrombosis of the right pulmonary artery. Tex Heart Inst J 2001;28:149-51.

8 Powers WJ, Rabinstein AA, Ackerson T, et al. 2018 Guidelines for the early management of patients with acute ischemic stroke: a guideline for healthcare professionals from the American Heart Association/American Stroke Association. Stroke 2018;49:e46-110.

9 Tudoran M, Tudoran C. High-risk pulmonary embolism in a patient with acute dissecting aortic aneurysm. Niger J Clin Pract 2016;19:831-3.

Copyright 2019 BMJ Publishing Group. All rights reserved. For permission to reuse any of this content visit

https://www.bmj.com/company/products-services/rights-and-licensing/permissions/

BMJ Case Report Fellows may re-use this article for personal use and teaching without any further permission.

Become a Fellow of BMJ Case Reports today and you can:

- Submit as many cases as you like

- Enjoy fast sympathetic peer review and rapid publication of accepted articles

- Access all the published articles

- Re-use any of the published material for personal use and teaching without further permission

For information on Institutional Fellowships contact consortiasales@bmjgroup.com

Visit casereports.bmj.com for more articles like this and to become a Fellow 